\title{
Haciendo las preguntas correctas. Foucault, poder y sexualidad.
}

\section{Making the right questions. Foucault, power and sexuality}

\author{
Paula Sequeira Rovira
}

Universidad Nacional de Costa Rica paulasr30@yahoo.com (COSTA RICA)

Recibido: 11.092014

Aceptado: 06.05.2015

\begin{abstract}
"qué ha sucedido para que nuestra sociedad, la sociedad occidental en general, haya concebido el poder de una manera tan restrictiva, tan pobre o tan negativa?" (Foucault 2010: 891).
\end{abstract}

\section{RESUMEN}

Este artículo tiene como propósito señalar la predominancia que ha existido en mirar la sexualidad desde un enfoque que tiene como horizonte la hipótesis represiva. Con ello se quiere decir que la sexualidad ha sido fundamentalmente analizada como un espacio reprimido y constreñido por diferentes agentes, legislaciones, instituciones, culturas, etc. Lo anterior ha estado influenciado en países de América Latina y otros lugares, por el uso de un marco de análisis del "poder para" y "poder sobre" que mira al poder como bueno o malo, dependiendo de su objetivo y resultados. Esta visión de la hipótesis represiva influye directamente en la forma en cómo ésta se investiga, las preguntas que se hacen y los resultados que se obtienen. Este documento busca plantear las posibilidades teóricas y analíticas que ofrece la teoría foucaultiana en estos estudios para permitir crear otro tipo de aproximación a estas temáticas que se aparten de mirar a la sexualidad como un sitio de represión o liberación.

\section{PALABRAS CLAVE}

Sexualidad, Foucault, hipótesis represiva, poder, investigación.

EMPIRIA. Revista de Metodología de Ciencias Sociales. N. ${ }^{\circ} 31$, mayo-agosto, 2015,, pp. 131-148. ISSN: 1139-5737, DOI/empiria.31.2015.14540 


\begin{abstract}
This paper aims to point out the prevalence that has existed in looking at sexuality from an approach that raises the repressive hypothesis as its horizon. This is to say that sexuality has been largely repressed and analyzed as a constrained space by different actors, laws, institutions, cultures, etc. The above has been influenced in Latin America by using a framework of analysis of «power to» and «power on», that looks al power as good or bad, depending on its purpose and results. This view of the repressive hypothesis directly influences the way in how it is investigated, the questions asked and the results that are obtained.This paper aims to present the theoretical and analytical potential of Foucault's theory in these studies in order to allow another type of approach to these issues to move away from looking at sexuality as a site of repression or liberation.
\end{abstract}

\title{
KEY WORDS
}

Sexuality, Foucault, repressive hypothesis, power, research.

\section{INTRODUCCIÓN}

El tema del poder, suele ser utilizado como referente explícito o implícito de los estudios en sexualidad, para acercarse a toda una variedad de situaciones, que van desde la búsqueda de placer, la negación o reconocimiento de derechos, el trabajo sexual, el amor, las identidades sexuales, la educación sexual, entre muchos otros. Sin embargo, en una importante cantidad de veces, dicho abordaje se basa en paradigmas que piensan al poder, como un agente represor y prohibitivo. Como complemento de lo anterior, en otras ocasiones, el poder también ha sido pensado como liberador, siempre y cuando el sujeto sometido, experimente un proceso de concientización que se supone lo llevará a un estado de liberación con respecto a ataduras pasadas, presentes o futuras, las cuales pueden ser de orden simbólico, espiritual o material.

Estos mismos marcos analíticos han sido utilizados por los estudios de género, cuando se refieren al poder desde la clásica dicotomía de poder-sobre y poder-para, con el objetivo de aludir a aquellas esferas de dominio individuales o colectivas que se realizan contando o no con la autorización de las personas.

Sin embargo, el presente artículo, el cual se basa en una perspectiva foucaultiana, percibe a ambas posiciones como objeto de crítica. Con base en ello, ya no se pone el énfasis en si una situación específica ha sido el resultado de años de sometimiento o ha sido producida por la toma de conciencia y/o liberación de las ataduras pasadas, sino que se busca poner en el centro del análisis los efectos productivos del poder, es decir, observar y analizar aquello que genera, que causa, que fabrica. Además, la perspectiva foucaultiana, pone énfasis en aquellos 
procesos que se plantean como "verdades", y que a su vez, entre otras cosas, producen sujetos y subjetividades.

Si bien el tema de la sexualidad convoca intereses muy diversos (muchas veces ya de por sí intensos), la profundización o continuación de investigaciones serias y académicas en esta materia, han sido escasas en un país como Costa Rica, donde se efectúa muy poca producción de este tipo. Pese a esto, cuando se realizan, muchas de ellas se quedan en los formatos de trabajos finales de graduación, generalmente encajonadas en las bibliotecas de las universidades nacionales. En el ámbito laboral, algunos organismos o personas en espacios universitarios se han interesado más puntalmente por indagar algunos aspectos específicos de la sexualidad. Actualmente, existen muchos tópicos que continúan sin investigarse y muchos otros son abordados a través de premisas que dan cabida a conclusiones que, casi siempre, llevan a los mismos lugares comunes de análisis.

De forma más sistemática, diversas ONGs o instituciones del Estado han venido realizando cierto tipo de trabajo sobre temáticas que versan sobre la explotación sexual comercial, el trabajo sexual, la salud sexual, las masculinidades o aspectos variados de las poblaciones LGBT (Lesbianas, Gays, Bisexuales y Transexuales). Generalmente estos estudios se realizan con datos cuantitativos (aunque en algunas ocasiones también con metodología cualitativa), pero tienen la particularidad de ser, no sólo muy descriptivos sino también muy laxos en sus abordajes teóricos. En algunos de ellos ni siquiera se utiliza un cuerpo teórico que sustente los hallazgos; además los análisis se componen de ideas muy generales de sus investigadores y las conclusiones son por lo general demasiado sintéticas (Por ejemplo: Suárez Rehaag, Daria y Madrigal Ballestero 2008; Chacón Alvarado, et.al. 2012; Consejo Nacional de Política Pública de la Persona Joven 2013; Chacón Alvarado et.al., 2012b; Chacón Alvarado, et.al. 2011; Ministerio de Salud, et al. 2012).

El interés de este trabajo es mostrar cómo muchos análisis sobre sexualidad en Costa Rica (y en otras partes del mundo), siguen enmarcándose en enfoques del poder como represor (no permitir, no tocar, no hacer, discriminar, violentar, etcétera), olvidando que el poder tiene más funciones y consecuencias que las de obstaculizar o prohibir acciones, tal y como lo recordaba Foucault, en varios de sus escritos. Para sustentar este razonamiento se utilizará principalmente, un texto reciente de investigación sobre la población LGBT en Costa Rica, que refleja bien el espíritu de los documentos que aquí se ponen como ejemplo.

\section{APORTES FOUCAULTIANOS PARA TRABAJAR EL TEMA DEL PODER Y LA SEXUALIDAD}

El filósofo francés Michel Foucault (1926-1984), es ampliamente citado como referente en temáticas de sexualidad así como en los abordajes vinculados al poder. Sin embargo, pareciera que cuando muchos lo utilizan para fundamentar un marco conceptual, lo hacen a través de alguna idea muy general 
de su planteamiento, y que por lo general, termina por contradecir lo que él efectivamente formuló.

Con respecto al tema del poder, Foucault tuvo en Nietzche, una gran influencia: "Nietzsche es quien ha puesto el poder como objetivo esencial del discurso, digamos filosófico." (Foucault, citado en Castro, 2011, 278). Su perspectiva se abocó no sólo a criticar ideas generalizadas que existían con relación al poder como negativo y prohibitivo, sino sobre todo a mostrar el carácter productor del mismo. No existe en Foucault un poder totalizante, un poder pensado con mayúscula, que abarca y domina a todos los seres vivos por igual $^{1}$. Algunos de los postulados con relación al poder desde esta perspectiva son los siguientes (Foucault, 2009, 102):

a) El poder se ejerce, no se posee;

b) El poder no es externo a las personas o a las relaciones humanas;

c) No existe una oposición binaria entre dominadores y dominados;

d) El poder se ejerce a través de objetivos;

e) El poder y la resistencia interactúan siempre juntos.

El poder en Foucault siempre va a ser parte de las relaciones humanas, es eficaz y funciona activamente en la producción de saberes, de cuerpos, de deseos, de sujetos, de sexualidades, de sexo $^{2}$.

Todo esto, ayuda a mirar al poder no como un fenómeno negativo o prohibitivo, sino parte de toda relación humana, y que a su vez, no se encuentra concentrada exclusivamente en instituciones específicas (iglesia, estado, escuela, ley, patriarcado). En un libro clave como Vigilar y Castigar (2012b) Foucault fue enfático en criticar las visiones que centraban su análisis en el poder soberano y trató de hacer un viraje que pensara al poder en términos disciplinarios. Se ocupó de reflexionar en cómo se construían los cuerpos en las prisiones, las escuelas, los hospitales. En un ejemplo clásico, el panóptico, se convirtió en parte fundamental de estos regímenes, donde sin siquiera tocar los cuerpos o estar dentro del mismo, se controlaba a las personas. Con ello, el poder adquiere características como el anonimato o la desindividualización (Foucault, 2012).

El poder disciplinar, por ejemplo, ayudó a construir cuerpos a los que se les enseñó, en el caso de los ejércitos, cómo tomar y disparar un rifle, cómo caminar, cómo vestir, cómo comportarse, etcétera. Posteriormente, Foucault también reflexionó sobre el poder biopolítico (Foucault, 2009) y el poder pastoral (Foucault, 2008), ambos catalogados, al igual que el poder disciplinario,

${ }^{1}$ En la novela 1984 de George Orwell, sólo para citar un caso ampliamente citado como referencia literaria, la idea del poder es contraria a la visión foucautiana.

2 Siguiendo estas las líneas de análisis, Butler busca profundiza en las funciones productivas del poder en la construcción del sexo. La inteligibilidad humana está dada por la coherencia del sexo "...el poder efectivamente genera objetos de control, en el que el poder elabora todo tipo de objetos e identidades que garantizan la argumentación de regímenes regulatorios científicos. La categoría "sexo" es construida como un "objeto" de estudio y control, que asiste en la elaboración y justificación de regímenes de poder productivos” (Butler, 1996, 60).

EMPIRIA. Revista de Metodología de Ciencias Sociales. N. ${ }^{\circ}$ 31, mayo-agosto, 2015, pp. 131-148. ISSN: 1139-5737, DOI/empiria.31.2015.14540 
como formas más sutiles poder, que se encargan hoy de maximizar la vida humana y de guiar a las personas/ovejas, en busca de que ninguna se pierda. Hoy, recurrir a análisis que tomen como base el biopoder e inclusive el poder pastoral, resultan cruciales para las analíticas de género. Como puede desprenderse de esto, las posturas de Foucault, han sido muy diferentes de muchas de las clásicas perspectivas que ha utilizado el feminismo para criticar la situación de las mujeres e incluso de los hombres.

Sin embargo, a nivel nacional e internacional, los estudios de género, sexualidad, y aproximaciones queer, frecuentemente han recurrido la figura de Foucault para avalar o refutar algún planteamiento analítico. Si bien las referencias de su trabajo son muchas, esto no significa que a través de él, se hagan las preguntas correctas y que por lo tanto, esto lleve al desarrollo de una buena investigación, desde el punto de vista metodológico, teórico y de resultados. De hecho, una gran cantidad de trabajos latinoamericanos sobre género, siguen enmarcándose en coordenadas de análisis que plantean un vaivén teórico entre concepciones de un poder malo y un poder bueno ${ }^{3}$. Para dar cuenta de ello, utilizaremos un planteamiento realizado por la mexicana Marcela Lagarde, quien es uno de los referentes teóricos más recurrentemente citados en los estudios de género, al menos en los países centroamericanos. En un texto bastante reciente, y haciendo referencia a Foucault la autora señala:

"El poder cristaliza en las más variadas instituciones civiles y estatales. En esa dimensión, es el espacio y el momento de tensión en el ejercicio de la dirección y el dominio del grupo dominante sobre el conjunto de la sociedad, tal como ha observado Gramsci (1975)... Todas las relaciones implican el poder, tal como lo ha señalado Foucault (1980). El poder consiste, fundamentalmente, en la posibilidad de decidir sobre la vida del otro; en la intervención con hechos que obligan, circunscriben, prohíben o impiden, Quien ejerce el poder somete e interioriza, impone hechos, ejerce el control, se arroga el derecho al castigo y a conculcar bienes reales y simbólicos: domina. Desde esta posición enjuicia, sentencia y perdona. Al hacerlo, acumula más poder." (Lagarde 2012: 469).

A pesar de citar a Michel Foucault, los comentarios hechos por la antropóloga mexicana, contradicen lo que el autor francés planteó en su corpus teórico. Lagarde no hace más que avalar una visión jurídica del poder, que el mismo Foucault tantas veces trató de criticar. Ella proporciona una mirada de lo que en los estudios de género se conoce como "poder-sobre", que se presenta como un polo negativo del poder al implicar situaciones de sometimiento,

${ }^{3}$ Tal y como lo dicen Berná et.al. (2012) en un trabajo del Estado español, su lógica sigue una idea represiva del poder, donde un "poder" debe ser destruido para conseguir otro mucho más benevolente: "Buscamos facilitar la generación de buenas prácticas en las que los sujetos se empoderen y puedan enfrentarse a las consecuencias negativas de ese estigma de género, las diversas manifestaciones del estigma derivado de un sistema de género heteropatriarcal basado en la desigualdad y ejercicio de la violencia y poder. En resumen nuestros intentos nos abocan finalmente a soñar con la ruptura del sistema actual de identificación y de ejercicio del poder." Otros ejemplos se pueden encontrar en: Casas \& Ahumada, 2009; De Ussel, 1993; Rodríguez, 2014, etc.

EMPIRIA. Revista de Metodología de Ciencias Sociales. N. ${ }^{o}$ 31, mayo-agosto, 2015, pp. 131-148. ISSN: 1139-5737, DOI/empiria.31.2015.14540 
violencia, subordinación, humillación, opresión, etc ${ }^{4}$.

La misma Lagarde, más adelante en este mismo texto dirá que: "El poder se define también como autoafirmación de los sujetos para vivir la vida, es decir, se define en sentido positivo y no implica, en este caso, la opresión de otros. Este es el poder al que aspiran los oprimidos." (Ídem). Para la autora mexicana, el "poder" deseado, implica un proceso de concientización, que dará como resultado la liberación de los sujetos dominados. Lo anterior ha sido generalmente comprendido como "poder-para" 5 .

Sin embargo, desde una perspectiva foucaultiana, los análisis que toman al poder como parte de su estudio, tendrían que trascender el mirarlo como bueno o malo, porque el mismo poder, no es necesariamente, ni una cosa ni otra. Foucault fue muy claro cuando decía que las personas no deberían “....considerar al poder como un fenómeno de dominación macizo y homogéneo -dominación de un individuo sobre los otros, de una clase sobre las otras" (Foucault 2000: 38). Para él, es mejor pensar en una suerte de circulación del poder (Ídem); es decir, no es algo, que está estancado en las manos de unos pocos (hombres, heterosexuales, capitalistas, reyes, clase alta, políticos) y del que otro grupo adolece o está en proceso de conseguir (mujeres, homosexuales, lesbianas, proletarios, súbditos, clase baja, ciudadanos). Lo anterior es lo que Foucault criticaba como la visión jurídica del poder, la cual ciertamente, es muy atractiva $\mathrm{y}$ aparece con mucha regularidad en los textos que manejan este tema como base de sus análisis. No es por supuesto, que Foucault negara o fuera ingenuo de la existencia de este tipo de acciones (someter, dominar, discriminar, esclavizar), sino que él creía que el pensamiento arriba mencionado era una pequeña parte de los efectos del poder y su crítica reiterativa servía, más bien, para enmascarar

${ }^{4}$ Otro ejemplo de poder-sobre en un trabajo reciente dice lo siguiente: "El poder en el ámbito de las relaciones personales tiene un sentido análogo a fuerza, capacidad, dominio, violencia... En la vida sexual, esta idea de dominio sobre sí y sobre los otros u otras surge claramente vinculada a los problemas de relación y del deseo, y permite aproximarse a la percepción de sentimientos como los celos, abandono, control y falta de control sobre los sentimientos." (Rodríguez, 2014, $44)$.

${ }^{5}$ Estos conceptos (poder-para y poder-sobre) han sido fundamentales en las teorías de género. Son el corpus básico de los planteamientos que se supone llevarán al empoderamiento y liberación femenina (y también humana), de los estragos cometidos por el sistema que se ha llamado "patriarcado". Por ejemplo, en esta misma línea, Magdalena León (1998) señala la importancia de diferenciar los tipos de poder existentes, entre estos destaca: a) el poder sobre (se caracteriza por ser "el más familiar y común", puede ser violento); b) poder para (produce cambios, "es un poder generativo o productivo" pero además "abre posibilidades y acciones sin dominación"; c) poder con (se manifiesta cuando un colectivo "presenta una solución compartida a sus problemas"); y d) poder desde dentro o poder del interior (tiene que ver con "la habilidad de resistir el poder de otros mediante el rechazo a las demandas indeseadas"). (Ídem: 16-19). Aunque la autora realice esta división, sigue prevaleciendo la idea de que hay un poder malo y otro bueno, a saber, el poder-sobre y el poder-para (que adjunta al postulado b, c y d) respectivamente. A pesar de citar a Foucault y resaltar su importancia, la división antes señalada no continúa con las líneas analíticas foucaultianas, no sólo por señalar que uno es más bondadoso que el otro, sino también porque es ilusorio pensar que existen relaciones sin poder. 
otro tipo de sus cualidades, que son las que se deberían analizar: "Se mantiene ese discurso sobre la moderna represión del sexo. Sin duda porque es fácil de mantener" (Foucault 2009: 5).

El mismo Foucault, llamaba a sospechar del concepto de represión (Foucault 2000: 30). Para él, esta idea está sustentada por un modelo de poder soberano, donde existe una figura central, generalmente representada de forma metafórica por el rey, quien es el que manda, decide y somete. El rey tiene el derecho de decidir sobre la vida y muerte de sus súbditos. Los análisis que se desarrollan basándose en este modelo, se sustentan en la atención o estudio de instituciones fundamentales del ordenamiento social (es decir, en esta visión existe un centralismo en pensar que el poder está concentrado en instituciones como el Estado, la iglesia, la escuela, ejercito, etc.). Desde la mirada habitual de los estudios de género, el poder del soberano se asemeja a las ideas asociadas al poder-sobre, representado clásicamente en aquello que el feminismo ha entendido como el patriarcado o sus efectos. En todo caso, los abordajes de aspectos sobre sexualidad que se realizan en Costa Rica y muy probablemente en muchas otras partes del mundo, suelen quedarse en este ámbito de análisis.

\section{EL PODER DEL CLOSET O EL CLOSET DEL PODER}

Aunque se cite a Foucault, la perspectiva que mira la sexualidad desde un poder represor, que la obliga a negarse a sí misma, es más bien cercana a las proposiciones del médico austrohúngaro Wilhelm Reich y al sociólogo alemán Herbert Marcuse. Así por ejemplo, los aportes marcusianos utilizaban a Freud y a Marx como soporte teórico y, en términos generales, planteaban que la civilización ha reprimido a las personas y a sus sexualidades: "En un orden represivo, que refuerza la ecuación entre normal, socialmente útil y bueno, las manifestaciones del placer por sí mismo deben aparecer como fleurs du mal" (1995: 58). Para Marcuse, desde los inicios de la historia, siempre hubo dominados y dominadores, los primeros representados por el padre y los segundos por las mujeres y sus hijos (Ídem, 67). Para él, la formación de la civilización ha provocado la represión de los instintos, entre ellos la sexualidad (Eros). La sociedad actual, necesita entonces que exista una contención sobre los deseos, para que sus energías se puedan enfocar en el trabajo. El objetivo de esta teoría es mostrar estos aspectos para poder liberarse de la dominación impuesta a la sexualidad. "La imagen de una cultura no represiva, que hemos extraído de una tendencia marginal en la mitología y el psicoanálisis, aspira a una nueva relación entre los instintos y la razón”. (İdem: 185).

Se pueden encontrar infinidad de ejemplos de esta visión en los documentos relacionados con temas de sexualidad. Para ejemplificar y a la vez, criticar lo

\footnotetext{
${ }^{6}$ Sin pretender ser exhaustivos, otras discusiones del poder en Foucault se pueden encontrar en: Foucault, 2001; Foucault, 2012; Foucault, 2012a; Foucault, 2012b; Foucault, 2008; Foucault, 1996.
}

EMPIRIA. Revista de Metodología de Ciencias Sociales. N. o 31, mayo-agosto, 2015,, pp. 131-148. ISSN: 1139-5737, DOI/empiria.31.2015.14540 
antes señalado, utilizaremos un tema recurrentemente empleado en los estudios o discursos de poblaciones gays y lésbicas, en su versión de poder-sobre o de poder-para, a saber, la alusión al closet o armario ${ }^{7}$ como sitio de sujeción ${ }^{8}$. En boca de algunos que han trabajado sobre el closet éste es "el símbolo de la vergüenza y de la sumisión a la opresión” y se supone que una vez que se sale de él es cuando verdaderamente se puede " "ser" como se "es" "(Caamaño 2005: 37). Eve Kosofsky Sedgwik (1998) quien trabajó este tema planteó que: "El armario es la estructura que define la opresión gay de este siglo" (Ídem: 96). Además, pensaba que tanto el vivir como el salir del closet/armario ${ }^{9}$ eran experiencias que podrían extenderse a poblaciones cercanas a los gays, como por ejemplo a sus familiares y amigos (el hecho de que en ciertos espacios, se acepte o se trate de esconder que se tiene un hijo gay).

Entonces, la visión más difundida sobre el closet ha supuesto que éste es una metáfora para aquel lugar simbólico, que posibilita el que las personas se resguarden de ataques discriminatorios (homo o lesbofobia, etc.) y que a su vez no permite mostrar quien realmente se es (oculta el yo). Desde esta perspectiva, el closet es una especie de salvaguarda en un sistema que acepta como válida una única identidad sexual y que podría actuar con violencia si la información cae en manos equivocadas (poder-sobre). Es en todo caso, un secreto que se guarda con recelo:

${ }^{7}$ En este artículo se utiliza prioritariamente el concepto "closet" y no "armario", pues el primero es más utilizado en países como Costa Rica, para designar este tipo de situaciones, sobretodo relacionadas con personas de la comunidad LGBT.

${ }^{8}$ El closet es una referencia, que al menos en Occidente es muy utilizada por las poblaciones LGBT. De hecho, a nivel internacional existe el "Día para Salir del Closet", celebrado el 11 de octubre y avalado como un espacio de lucha en el país (Abarca: 2013). En Costa Rica y probable en otros países de América Latina y en España, existe poca preocupación en discutir sobre los significados adyacentes a esta noción. Seidman, Meeks y Traschen (2002: 427) han alegado al menos tres razones por las que consideran que este término merece algunas reservas de uso. Primero, normaliza la identidad lésbico-gay, por lo que no cuestiona la sexualidad que se produce a través del binomio heterosexual-homosexual. Segundo, al centralizar la atención en la identidad sexual que se debe declarar sin vergüenza alguna, el salir del closet se convierte en el "acto político supremo", que se cree socavaría el sistema heterosexista. Tercero, las narrativas que se crean por la salida del closet, introducen diferencias y divisiones entre los que están "afuera" y los que están "adentro".

9 "Salir" del closet implica realizar acciones que llevarán al sujeto a confesarse. No puede haber "salida" de este lugar sin una confesión, aunque en primer lugar ésta sea hacia uno mismo. Sin embargo, esta confesión se piensa como subversiva, contestaría a un cierto poder que es pensado como moralista, como represor. Sentirse que se está "afuera" de un closet simbólico implica una tecnología del yo, entendiendo esta última como aquellas tecnologías que “...permiten a los individuos efectuar, por cuenta propia o con ayuda de otros, cierto número de operaciones sobre su cuerpo y su alma, pensamientos, conducta, o cualquier forma de ser, obteniendo así una transformación de sí mismo con el fin de alcanzar cierto estado de felicidad, pureza, sabiduría o inmortalidad." (Foucault, 1996, 48). Desplazarse "fuera de", como se verá más adelante, solamente fortalece la creación de un sujeto específico que se diferencia de los demás, pero que simplifica, nuevamente, su relación personal con el poder.

EMPIRIA. Revista de Metodología de Ciencias Sociales. N. ${ }^{\circ}$ 31, mayo-agosto, 2015, pp. 131-148. ISSN: 1139-5737, DOI/empiria.31.2015.14540 
"Uno de los actos entonces más repudiados socialmente es el de hacer pública la propia preferencia, lo que no se perdona es que un gay lo diga abiertamente y menos aún que lo exprese orgullosamente. Por el contrario, se espera que los sujetos sexo-diversos tengan la decencia de mantenerse en el closet de donde se espera que no salgan" (List Reyes 2010: 140).

Sin embargo, desde otro tipo de enfoque más cercano a las corrientes foucaultianas, el closet puede tener otro tipo de aproximaciones analíticas. Por ejemplo, cuando Judith Butler (2000), se pregunta qué significa cuando ella misma dice que es una lesbiana, también se cuestiona por las implicaciones del closet y por cuáles son los riesgos, no de violencia o de discriminación, sino de regulación de la identidad que implican utilizar esta metáfora:

Convencionalmente, uno sale del closet... entonces salimos del closet pero ¿para ir a dónde? ¿a un nuevo espacio sin límites?... Curiosamente, la figura del closet es la que produce esta expectativa y la que garantiza su insatisfacción. Pues estar "afuera" siempre depende hasta cierto punto de estar "adentro"; gana su significado dentro de la polaridad. Por lo tanto, el hecho de estar "afuera" debe producir el closet una y otra vez para mantenerse como "afuera" (Butler 2000: 91).

Butler no tiene como meta revisar los inconvenientes que presenta el closet (poder-sobre), ni los beneficios variados que ha tenido la decisión de salir de él (poder-para). Ella se decanta por preguntarse más bien sobre las siguientes líneas: ¿qué significa decir que poseo una cierta identidad?, ¿qué implicaciones tiene la palabra closet?, ¿qué procesos han creado ese yo que se piensa "afuera" o "adentro" de un espacio simbólico?, ¿salir del closet implica ser más libre? Lo que cuestiona Butler es la idea un yo verdadero que se muestra en el "afuera" de quien ha salido a la luz pública. La lógica aquí, ya no está en las dicotomías antes mencionadas, sino en poner atención a los procesos que han llevado a los sujetos a pensarse y a expresarse públicamente como una u otra cosa y que fortalecen con la metáfora del closet o armario.

En una línea de abordaje parecida, Seidman, Meeks y Traschen (2002) se cuestionan sobre el closet, con el objetivo de trascender las clásicas implicaciones represoras de éste. Para ellos, la idea del closet ayuda a formar la idea de un "yo homosexual original y anteriormente formado, que está constreñido "en" el closet" (Ídem: 431). Además señalan que al alejarse del paradigma represor, se pueden ver al menos dos efectos productivos de este espacio. Primero, el ocultamiento realizado por quien se siente dentro del closet, tiene resultados, no sólo de proteger a esas persona de las consecuencias propias de una exposición, sino que además facilitan la creación de "un espacio psíquico «protegido»", que construiría un "yo gay". En segundo lugar, otro de los efectos productivos del closet sería la creación de comunidades de apoyo que se puede hacer durante o posterior a la salida del mismo (Ídem: 431-432). 
El closet pareciera ser entonces un dispositivo ${ }^{10}$, en el sentido foucaultiano del término, el cual tiene por función subjetivizar tanto a las personas que se sienten "dentro" (homosexuales o lesbianas no declarados), como a las que se sienten "fuera" (no sólo por no haber tomado la decisión de "salir", sino también a quienes creen que nunca estarán en él, como por ejemplo los heterosexuales). Foucault creía que el dispositivo era "una gran red de superficie en la que la estimulación de los cuerpos, la intensificación de los placeres, la incitación al discurso, la formación de conocimientos, el refuerzo de controles y las resistencias se encadenan unos con otros..." (2009: 112). Uno de los efectos del dispositivo es la producción de sujetos. En este caso, el closet crea un "yo lésbico" o un "yo homosexual" que es atornillado a una serie de símbolos, ideas, proposiciones y saberes provocando la creencia de que alguien es efectivamente de una u de otra manera. La "verdad" del yo se reduce a una cuestión de "afuera" o "adentro" con todo lo que esto significa. Sin duda, la noción "closet" ha generado toda una serie de discursos, investigaciones y proclamaciones públicas sobre él. Tal y como se dijo anteriormente, el dispositivo del closet no sólo intensifica la proximidad de relaciones de quienes salieron de él (crea comunidades en contra o a favor), sino que además favorece la consolidación de las definiciones recreadas a través de la construcción de la subjetividad. Para ser más exactos, su constitución también profundiza la técnica de confesionalidad de la sexualidad que ha sido tan promovida en nuestras culturas occidentales.

El ejemplo del closet/armario, sirve aquí para mostrar las potencialidades analíticas de las posiciones que trasciendan las clásicas discusiones de podersobre o poder-para de los estudios de género, y que generalmente son aplicados también a los estudios en sexualidad.

\section{EL PODER-SOBRE DE LA POBLACIÓN LGBT: UN ESTUDIO RECIENTE}

En este apartado se hará alusión a un trabajo reciente, elaborado en Costa Rica titulado "Sondeo de Percepción de los Derechos Humanos de las Poblaciones LGBT en Costa Rica en el año 2012" (Chacón Alvarado, et.al.: 2012), para ejemplificar lo que se ha venido planteando sobre la tendencia en los análisis de sexualidad de pensar al poder como coercitivo (producto inevitable del sistema represivo existente) o como redentor (como consecuencia de algún tipo de "liberación sexual"). Dicho estudio tiene como población meta, lo que sus investigadores llamaron "personas sexualmente diversas" ${ }^{11}$. La 2011.

${ }_{10}$ Para profundizar en el significado de los dispositivos, revisar Foucault, 2009 y Agamben,

i1 Los términos "personas sexualmente diversas" (Chacón Alvarado et.al.: 2012), o personas "sexodiversas" (List Reyes: 2010) han sido utilizados para designar exclusivamente a personas lesbianas, homosexuales, bisexuales, transexuales, transgénero y posiblemente también a los intersexuales. Pero ¿qué implica decir que alguien es sexo-diverso y otro no? Se sobreentiende que el énfasis buscado está en la posibilidad de marcar una diferencia con los cuerpos que la sociedad y

EMPIRIA. Revista de Metodología de Ciencias Sociales. N. 31, mayo-agosto, 2015, pp. 131-148. ISSN: 1139-5737, DOI/empiria.31.2015.14540 
investigación parte de las siguientes preguntas: “QQué pasa en Centroamérica entonces?, ¿por qué el escaso reconocimiento de los Derechos Humanos de las poblaciones LGBT?, ¿por qué se perpetúa la invisibilización?, ¿por qué la discriminación y la violencia continúan siendo la cotidianidad de las personas LGBT?" (Chacón op.cit.: 2012, 9). Para responder dichas interrogantes se prepararon grupos focales con personas que trabajan en organizaciones de derechos humanos de la población LGBT, encuestas en línea a lesbianas, homosexuales, bisexuales y trans, y entrevistas semiestructuradas a instituciones gubernamentales y a lo que llamaron "organizaciones aliadas". Nótese como las preguntas iniciales arriba planteadas, parten de la premisa de la represión como brújula de navegación, por lo que desde esta perspectiva el sometimiento y la violencia marcan las coordenadas de estudio.

Si bien, las preguntas de una investigación son fundamentales en el proceso de formulación y recolección de datos, las ideas subyacentes que hay detrás de ellas, guiarán la forma en cómo se concibe la realidad a estudiar. Desde el abordaje foucaultiano, las interrogantes que orienten los estudios se sustentan en otro tipo de acercamiento:

La pregunta que querría formular no es: ¿por qué estamos reprimidos?, sino: ¿por qué decimos con tanta pasión, tanto rencor contra nuestro pasado más próximo, contra nuestro presente y contra nosotros mismos que estamos reprimidos? ¿Mediante qué espiral hemos llegado a afirmar que el sexo es negado, a mostrar ostensiblemente que lo ocultamos, a decir que lo silenciamos... (Foucault 2009: 9).

Esta idea del sexo negado es especialmente penetrante en los estudios de sexualidad en Costa Rica y particularmente constante en los análisis de poblaciones LGBT. Una vez más, no es que Foucault desconociera los procesos de represión sexual, que diferentes personas pudieran tener, sino que para él los análisis deberían trascender estas premisas clásicas de aproximación y mirar otras situaciones que se pasan por alto o que parecen intrascendentes. Es común encontrar entonces, este tipo de abordajes en una gran cantidad de trabajos de sexualidad, donde casi siempre se constatan preguntas y lugares comunes de análisis, como los ya antes citados.

Para seguir en esta misma línea de análisis, en la investigación anteriormente citada (Chacón Alvarado et. al., Op.cit.), el apartado de entrevistas a personas de instituciones gubernamentales y "aliadas", estuvieron enfocadas en cinco

la medicina ha denominado hombres y se sienten atraídos por los cuerpos que se han denominado como de mujeres y viceversa (esto porque algunas personas trans también se consideran heterosexuales). Pero ¿qué implica ser diverso sexualmente hablando? Si se piensa que sólo los gays y las lesbianas son diversos sexuales ¿esto implicaría que los heterosexuales serían sexo-semejantes? Utilizar esas categorías para describir a unos grupos y a otros no, es desconocer u ocultar la diversidad de prácticas, experiencias, formas de vivir y las identidades que existen dentro del mundo heterosexual y dentro de todos los humanos. Aunque el término, simplemente fuera utilizado para hacer una diferenciación tajante, su uso lleva a la reproducción de esencialismos que los estudios en sexualidad debería de tratar de minimizar.

EMPIRIA. Revista de Metodología de Ciencias Sociales. N. o 31, mayo-agosto, 2015,, pp. 131-148. ISSN: 1139-5737, DOI/empiria.31.2015.14540 
variables, las cuales son: a) conocimiento de la normativa, b) valoración de la normativa, c) valoración de los mecanismos para ejecutar las normas, d) obstáculos, e) avances. Tal y como se ha señalado anteriormente, en la visión jurídica del poder, buena parte del escrutinio se queda concentrada en aspectos de ausencia o presencia de legislación. Esto se convierte, para dichos estudios, en una línea estratégicas de observación porque se cree que en buena medida, el poder está concentrado aquí. Sin embargo, desde una visión foucaultiana, habría que priorizar otros aspectos que no centralicen el análisis en el poder de la legalidad. Por ejemplo, ya a mediados de los setenta, Foucault (2010) nos recordaba que deberíamos dejar de hacer preguntas relacionadas con el poder como represor, por lo tanto no cuestionar "dónde está el poder, quién lo detenta, qué reglas lo administran, cuál es el sistema de leyes que el poder establece sobre el orden social" (2010: 890). Al menos desde una visión foucaultiana, los análisis de sexualidad y de poder, deberían cuestionarse otros aspectos como por ejemplo, la construcción de saberes, las subjetividades sexuales o la institucionalización de la confesionalidad sexual.

Más adelante, en el documento aquí analizado (Chacón Alvarado et. al. op.cit), se señala que la encuesta fue contestada por 496 hombres, 337 mujeres, 2 mujeres trans y 4 hombres trans, dando un total de 845 personas, de las cuales 456 se declararon homosexuales, 240 lesbianas, 144 bisexuales y 5 heterosexuales. A pesar de que ésta se respondió a través de una computadora y de forma confidencial, para sus investigadores existe la premisa de que, tanto poblaciones trans como la lésbica contestan en menor medida por la opresión que existe hacia ellos y ellas. Por ejemplo, ante la poca participación de personas trans las hipótesis del estudio primero se encaminaron a señalar el acceso diferenciado a internet o la escasa organización de esta población. Sin embargo, posteriormente se sentencia: "Estas condiciones podrían haber interferido en su participación, además de otras variables como el temor, la persecución, sanción social real e interiorizada..." (Ídem: 28). La misma idea es aplicada para explicar la menor participación de lesbianas, pues una de las hipótesis es también "el temor a (la) discriminación" (Ídem). Si el instrumento se hacía en forma anónimo y a través de una computadora en cualquier lugar, ¿por qué al equipo investigador llega a esta conjetura?

Foucault (2009) fue crítico en cuestionar los planteamientos que ponían como fundamento de su análisis la "hipótesis represiva", es decir, la idea de que en sexualidad lo que prima es la coerción (no hagas, no digas, no toques etc.). Estas nociones recrean la idea de que todo lo sexual está principalmente constreñido por una serie de instituciones sociales. Para él, más bien, a lo largo de los últimos siglos se han producido gran cantidad de discursos y saberes que se fueron forjados por personas como sacerdotes, médicos, juristas, profesores, entre otros, y que en buena medida, han conformado lo que hoy creemos que "es" la sexualidad.

Más adelante en el trabajo de Chacón Alvarado et.al. (2012), se sigue utilizando la hipótesis represiva como marco explicativo. Por ejemplo, después del conteo de las respuestas, se obtuvo que quienes manifestaron hacer sufrido 
violencia sexual en algún momento de sus vidas, fueron 13 homosexuales y 3 lesbianas. La explicación de por qué existen un mayor número de hombres gays que respondieron afirmativamente el haber vivido esta situación, fue la siguiente:

"La segunda vía de análisis se asocia con el bajo número de mujeres lesbianas que indicaron haber sufrido violencia sexual. No obstante, se podría plantear como hipótesis que la resistencia social por parte de las mujeres para aceptar haber sufrido esta forma de maltrato es tan fuerte y con secuelas tan graves, que se genera, en muchas ocasiones, la negación; donde las lesbianas no estarían exentas de ella" (Ídem: 36).

Si el instrumento es anónimo ¿por qué deberían las lesbianas resistirse más que los homosexuales a aceptar un hecho como ese? Parece desprenderse de lo anterior, que para los investigadores la violencia sexual es más traumática para las lesbianas que para los hombres gays. Es decir, en este apartado no sólo se presenta una hipótesis represiva sino además una hipótesis victimista de esta dolorosa situación, que pone siempre a las mujeres como las eternas víctimas de la sociedad, a pesar de que los mismos números que se recogieron en la investigación no avalen esta conjetura.

Luego de su lectura, el documento aquí analizado, fortalece la idea de un poder centralizado. Es decir, existe la sensación de que existe un GRAN poder contra el que se debe luchar y que posterior a su derrota, ocurrirá una especie de liberación ${ }^{12}$. En este caso, ese poder represor parece ser el sistema heteronormativo, el cual produce discriminación, violencia, homofobia, etc. Tanto es así que una de las conclusiones del documento señala: "Si las personas tomaran conciencia del poder que tiene asumirse como LGBT frente al sistema heterocéntrico, se estaría dando un salto cualitativo hacia la transformación real y la verdadera igualdad social." (Ídem: 49). Sin embargo, uno debería preguntarse si las ideas detrás del "poder-para" en clave de identidad (tomar "conciencia del poder que tiene asumirse como LGBT") es una condición efectiva de transformación sistémica.

En una entrevista que concedió Foucault en los ochentas el francés señaló:

"[Una] cosa en la que desconfiar es la tendencia a relacionar la cuestión de la homosexualidad con el problema de "¿Quién soy yo?» y «¿Cuál es el secreto de mi deseo?»Quizás sería mejor preguntarse: "¿Qué relaciones, a través de la homosexualidad, pueden ser establecidas, inventadas, multiplicadas, y moduladas?» El problema no es descubrir en uno mismo la verdad del sexo de uno, sino, más bien, usar la sexualidad propia, en adelante, para llegar a una multiplicidad de relaciones." (Citado por Kingston 2009: 9).

12 Una idea parecida está contenida en la película Down with Love (2003), donde la protagonista, Barbara Novak, interpretada por Renée Zellweger, escribe un libro en el que critica al amor romántico y el sometimiento que este produce a las mujeres por parte de los hombres. Novak las insta a que inviertan ese tiempo en otras cosas más provechosas y que tengan sexo sin compromisos. El libro se vuelve un éxito a nivel internacional, provocando que las mujeres de todo el mundo se "liberen" de la represión que vivían a causa de este hecho.

EMPIRIA. Revista de Metodología de Ciencias Sociales. N. ${ }^{\text {o } 31, ~ m a y o-a g o s t o, ~ 2015, ~ p p . ~ 131-148 . ~}$ ISSN: 1139-5737, DOI/empiria.31.2015.14540 
Claramente aquí Foucault no está interesado en el problema de identidad, más bien dice "desconfiar" de la propensión a utilizarla con tanta insistencia, en esta entrevista él se interesa más bien por los lazos sociales que se pueden formar en las relaciones humanas. Preguntarse por "la verdad del sexo de uno" es una forma de esencializar la identidad y presentarla como una verdad incuestionable.

Recordemos que por ejemplo, Seidman, Meeks y Traschen (2002: 427) criticaban las ideas detrás del closet, por considerar que éste ayudaba a promover la noción de que al salir de él se forjaba el "acto político supremo", que ayudaría a minar el sistema heteronormativo. Existen posiciones que, como ya se ha dicho, cuestionan la recomendación del equipo investigador como herramienta de resistencia y rebeldía. La idea de un "verdadero yo" constreñido por una conjunto de instituciones sociales que lo obligan a no mostrar quien "realmente no se es"13 puede ser un postulado engañoso, aunque utilizado con fuerza por múltiples grupos como las feministas o movimientos de mujeres, las personas indígenas, afrodescendientes o personas con discapacidad, sólo para citar algunos casos.

En esta misma línea crítica Butler (2011), se pregunta por el acto de "convertirse en lesbiana" y las situaciones regulatorias que podría acarrear cualquier identidad sexual: "¿qué evitaría que el nombre de lesbiana se convierta en una categoría igualmente obligatoria?" (2011: 252). Es decir, lo que Butler cuestiona es la idea engañosa de que en sexualidad, la liberación vendrá cuando la represión estatal, religiosa e institucional se acabe, pues salirse de las relaciones de poder es un sin sentido. Por más "libres" que nos sintamos y que promovamos ser a los otros, el poder sigue presente en otros aspectos, con otras funciones, generando otros efectos tal vez mucho más sutiles. Por eso, es importante cambiar el registro de análisis y comenzar a hacernos otro tipo de preguntas en materia sexual, tal vez más interesantes y que den cabida a resultados más sustanciosos.

${ }^{13}$ La idea de una existencia anterior y limpia de asperezas en la identidad es una noción común en muchos espacios de discusión que aparecen cuando las personas hablan de género y de sexualidad. En algunas ocasiones, este pensamiento ha servido como bandera de defensa contra los ataques homofóbicos hacia la población LGBT. Uno de los líderes del movimiento gay en Costa Rica, solía decir que posterior a que los heterosexuales (hombres) tomaban de más, rápidamente aparecía su lado homosexual. Sin embargo, su contraparte nunca fue si quiera una opción para él, es decir, nunca se preguntó: ¿si los gays toman de más, esto implicaría la aparición de su lado heterosexual? Es como si para defenderse de la exclusión por orientación o identidad sexual, se necesitara una bandera de la identidad pura, incorrupta, nítida, sin grietas que además asegurará la subversión socio-cultural. Si la heterosexualidad se utiliza por algunos líderes del movimiento LGBT, como una identidad frágil (el alcohol por ejemplo, puede debilitarla o "exponerla" tal cual es) ¿por qué no se hace lo mismo con otras identidades? 


\section{REFLEXIÓN FINAL}

El análisis aquí presentado pretende cuestionar, la tendencia marcada en los estudios de sexualidad y de género, de entender al poder en forma negativa o liberadora. Como también se dijo anteriormente, el comprenderlo de una o de otra manera, ofrece a los investigadores una serie de premisas y resultados completamente diferentes. Si el poder-sobre y el poder-para han sido las coordenadas que definen gran parte de cómo se han manejado estas temáticas, la perspectiva foucaultiana permite desligarse de estas posiciones y poner la mirada en otros aspectos como la creación de saberes, las tecnologías, los dispositivos, los procesos de subjetivación adyacentes a ella, etcétera.

El documento que aquí se analizó (Chacón Alvarado et. al., 2012) no pretende ponerse como reflejo de todos los estudios sobre sexualidad realizados en Costa Rica o América Latina. Más bien, se buscó presentarlo como ejemplo de nociones y lógicas que ponen su atención únicamente, en los efectos destructivos de la coerción sexual. Dicho trabajo estaba claramente sustentado en al menos tres grandes líneas analíticas: a) hipótesis represiva, b) enfoque institucional y c) modelo soberano. Foucault recordaba que "No se trata de preguntar: «¿De dónde viene el poder o a dónde va?», sino: «¿Por dónde circula y cómo ocurre eso, cuáles son las relaciones de poder, cómo podemos describir algunas de las principales relaciones de poder que se ejercen en nuestra sociedad?»" (2010b: 812).

Sin duda, muchos trabajos en sexualidad, relacionados a la población LGBT, e inclusive a los heterosexuales, suelen partir de abordajes que avalan la hipótesis represiva, que Foucault tanto criticó. Esos estudios o planteamientos, mantienen una espiral de comodidad que refuerzan expresiones, abordajes y situaciones reiteradas que se presentan como universales.

Asimismo, parece importante recalcar, la importancia de cuestionar los términos reiterados en materia de investigación sexual y que son constantemente utilizados sin que se produzca una mayor reflexión sobre los mismos. Frases como "sexualidad", "sexualidad sana", "sexualidad integral", "liberación sexual", "personas sexo-diversas", "diversidad sexual", etc., deben pasar por un proceso de reflexión por parte de quienes los utilizan. Inclusive, tal y como fue expuesto aquí, un término tan utilizado como "closet", merece una discusión más profunda: no sólo para mostrar la reiterada utilización de connotaciones represivas que hay de él, sino además para cuestionar una noción que se da por sentado en espacios nacionales e internacionales.

Habría también que llamar la atención sobre la tendencia que han mostrado trabajos en materia sexual en Costa Rica, de no utilizar casi ningún sustento teórico en su desarrollo. Estos se realizan tanto desde las organizaciones no gubernamentales como desde instituciones estatales (Por ejemplo: Suárez Rehaag, Daria y Madrigal Ballestero: 2008; Chacón Alvarado, et.al.: 2012; Consejo Nacional de Política Pública de la Persona Joven: 2013; Chacón Alvarado, et.al.: 2012b; Ministerio de Salud, et al: 2012). Es como si, en materia sexual, las vivencias personales de cada quien fueran suficientes, para

EMPIRIA. Revista de Metodología de Ciencias Sociales. N. ${ }^{\text {o } 31, ~ m a y o-a g o s t o, ~ 2015, ~ p p . ~ 131-148 . ~}$ ISSN: 1139-5737, DOI/empiria.31.2015.14540 
justificar los resultados de los estudios. Esto, bien puede hacerse por la premura de entregar un documento o por otro motivo como falta de interés en la lectura o por considerar a ésta como innecesaria. Sin embargo, la reflexión teórica es fundamental a la hora de investigar cualquier tema. Entonces, si nuestro objetivo como investigadores o interesados en la materia de sexualidad es ¿cómo hacer las preguntas correctas?, las respuestas a ella necesitarán una gran reflexión teórica y práctica de las diferentes situaciones.

Asimismo, parece importante recordar que Foucault tenía mucho cuidado en pensar cuáles serían las interrogantes que uno como investigador, debería hacer en un tema como el de la sexualidad. Como lo hemos visto, él se hacía muchas preguntas que ayudaban a dejar más claros sus planteamientos o a mostrar qué era lo que él mismo quería decir: "En consecuencia, no preguntar a los sujetos cómo, por qué y en nombre de qué derechos pueden aceptar dejarse someter, sino mostrar cómo los fabrican las relaciones de sometimiento concretas" (Foucault 2000: 50). Con esto se buscaba salirse de la clásica dicotomía del poder como bueno o malo y más bien se quiere ofrecer una base de diagnóstico que partiera de otro registro analítico.

¿Cuál es la alternativa presente aquí, frente a este tipo de estudios? ¿Cómo hacer para encontrar formas que nos ayuden efectivamente a hacer otro tipo de acercamientos teóricos?. La respuesta no está en el qué sino más bien en el cómo: “...las posibilidades reales de resistencia comienzan cuando dejamos de preguntarnos si el poder es bueno o malo, legítimo o ilegítimo e interrogamos sus condiciones de existencia" (Castro, 2011, 357).

En todo caso, este artículo no busca ofrecer las respuestas correctas a problemas de análisis en el campo de la sexualidad. Pretende más bien, generar una serie de discusiones básicas que permitan ayudarnos a producir preguntas pertinentes, sugestivas y oportunas, en una materia donde, con demasiada regularidad, se repiten los mismos cuestionamientos que llevan casi siempre a insistir en las mismas ideas manoseadas.

\section{BIBLIOGRAFÍA}

ABARCA, M. (2013): “A las puertas del closet” La Nación, Costa Rica, 2013.

AGAMBEN, G. (2011): “¿Qué es un dispositivo?” Sociología, (Trad. Roberto J. Fuentes Rionda), año 26, número 73, pp. 249-264.

BERNÁ, D., CASCONE, M., PLATERO, R. (2012): “¿Qué puede aportar una mirada queer a la educación? Un estado de la cuestión sobre los estudios sobre la LGTBfobia y educación en el Estado español" Scientific Journal of Humanistic Studies. 4(6), pp. 1-11.

BUTLER, J. (1996): "Sexual inversions" Feminist interpretations of Michel Foucault. (Susan J. Hekman, ed). Pennsylvania: The Pennsylvannia State University Press, pp.59-75.

BUTLER, J. (2000): "Imitación e insubordinación de género". Grafías de Eros. Buenos Aires: Edelp, pp. 87-113. 
BUTLER, J. (2011): El género en disputa: el feminismo y la subversión de la identidad. Trad. María Antonia Muñoz, 4ta reimpresión. España: Paidós.

CAAMAÑO M., Virginia (2004): "Voces marginales en "Bienvenido a tu Nueva Vida" de Uriel Quesada" Revista de Filología y Lingüística, pp. 35-42.

CASAS, L., \& AHUMADA, C. (2009): "Teenage sexuality and rights in Chile: from denial to punishment." Reproductive health matters, 17(34), 88-98.

CASTRO, Edgardo. (2011): Diccionario Foucault. Temas, conceptos y autores. Buenos Aires: Siglo XXI.

CHACÓN ALVARADO, E.; Ugarte, M. y Carvajal, N. (2011): Diversidad sexual en Centroamérica. Promoviendo los derechos humanos y previniendo la violencia de género: Investigación Hemerográfica, capítulo Costa Rica 2004-2011. Costa Rica: Centro de Estudios Internacionales.

CHACÓN ALVARADO, E. Sánchez Mora, A. y Brenes Hernández, P. (2012): Sondeo de Percepción de los Derechos Humanos de las Poblaciones LGBT en Costa Rica en el año 2012. Costa Rica: Centro de Estudios Internacionales.

CHACÓN ALVARADO, E., Brenes Hernández, P. y Sánchez-Mora, A. (2012b): Mapeo de actores estratégicos en materia de los derechos humanos de la población LGBT en Costa Rica. Costa Rica: Centro de Estudios Internacionales.

CONSEJO NACIONAL DE POLÍTICA PÚBLICA DE LA PERSONA JOVEN (2013) Segunda encuesta nacional de juventudes: informe de principales resultados. Costa Rica.

DE USSEL, J. I. (1983). "La sociología de la sexualidad en España: notas introductorias." Reis, pp. 103-133.

FOUCAULT, M. (1996): Tecnologías del yo y otros textos afines. Barcelona: Ediciones Paidós Ibérica.

FOUCAULT, M. (2000): Defender la sociedad. Curso del Collège de France (19751976). Trad. Horacio Pons. Fondo de Cultura Económica, Argentina.

FOUCAULT, Michel. (2001): Los anormales. Curso del Collège de France (19741975). Trad. Horacio Pons. Madrid: Ediciones Akal.

FOUCAULT, M. (2008): Seguridad, territorio y población. Curso del Collège de France (1977-1978). Trad. Horacio Pons. Madrid: Ediciones Akal.

FOUCAULT, M. (2009): Historia de la Sexualidad I. La voluntad de saber. Trad. Ulises Guiñazú. España, Tercera impresión.

FOUCAULT, M. (2010): “Las mallas del poder" Obras esenciales. III Estética, ética y hermenéutica. Trad. Ángel Gabilondo. España: Paidós.

FOUCAULT, M. (2010b): "Sexualidad y poder" Obras esenciales. III Estética, ética y hermenéutica. Trad. Ángel Gabilondo. España: Paidós.

FOUCAULT, Michel. (2012): El poder psiquiátrico. Curso del Collège de France (1973-1974). Trad. Horacio Pons, la ed. 3 a reimp., Buenos Aires: Fondo de Cultura Económica.

FOUCAULT, M. (2012a): Nacimiento de la biopolítica: curso en el Collège de France: 1978-1979. Trad. Horacio Pons. Buenos Aires: Fondo de Cultura.

FOUCAULT, M. (2012b): Vigilar y castigar: nacimiento de la prisión. 2da ed. 3era reimpresión. Buenos Aires: Siglo XXI.

KINGSTON, M. (2009): "Subversive Friendships: Foucault on Homosexuality and Social Experimentation" Foucault Studies, No 7, pp. 7-17.

KOSOFSKY SEDGWIK, E. (1998): Epistemología del armario. Trad. Teresa Bladé Costa. Barcelona: Ediciones de la Tempestad. 
LAGARDE Y DE LOS RÍOS, M. (2012): El feminismo en mi vida. Hitos, claves y topías. Gobierno de la Ciudad de México, Instituto de las Mujeres del Distrito Federal, México.

LEÓN, M. (1998): "El empoderamiento en la teoría y práctica del feminismo" Poder y empoderamiento de las mujeres. Primera reimpresión. Bogotá: Tercer Mundo Editores.

LIST REYES, M. (2010): "Hombrecitos o de cómo se espera que éstos sean" Disciplinas y prácticas corporales. Una mirada a las sociedades contemporáneas. Barcelona: Anthropos Editorial. México: Universidad Autónoma Azcapotzalco, pp. 115-146.

MARCUSE, H. (1995): Eros y civilización. Trad. Juan García Ponce. 3era ed., Barcelona: Editorial Ariel.

MINISTERIO DE SALUD, et al. (2012): Visualizando la salud reproductiva y la sexualidad desde diversas perspectivas: un análisis a partir de la Encuesta de salud sexual y reproductiva, Costa Rica: Ministerio de Salud.

RODRÍGUEZ, G. (2014): ““'Perdiendo los estribos”. Emociones y relaciones de poder en el cortejo". Desacatos. Revista de Antropología Social, (6), 35-62.

SEIDMAN, S., MEEKS, C. and TRASCHEN, F. (2002): "Beyond the Closet? The changing social meaning of homosexuality in the United States" Sexuality and Gender (Ed. Christine L. Williams and Arlene Stein), United States: Blackwell Publishers, pp. 427-445. 